\title{
A Simple HPLC-ELSD Method for Sugar Analysis in Goji Berry
}

\author{
D. Montesano, L. Cossignani, L. Giua, E. Urbani, M. S. Simonetti, and F. Blasi \\ Department of Pharmaceutical Sciences, Section of Food Science and Nutrition, University of Perugia, Via San Costanzo, \\ 06126 Perugia, Italy \\ Correspondence should be addressed to L. Cossignani; lina.cossignani@unipg.it
}

Received 12 November 2015; Accepted 10 January 2016

Academic Editor: Patricia Valentao

Copyright (C) 2016 D. Montesano et al. This is an open access article distributed under the Creative Commons Attribution License, which permits unrestricted use, distribution, and reproduction in any medium, provided the original work is properly cited.

Fructose, glucose, and sucrose were identified and quantified in commercial samples of Lycium barbarum L. fruits (goji berries) by high performance liquid chromatography-evaporative light scattering detector (HPLC-ELSD) method. This study described a rapid, simple, sensitive, selective, and reliable HPLC method suitable for the profiling of major sugars in berries, the evaluation of the nutritional/energetic properties, and assessment of the maturation stage. The proposed analytical method was validated and the results showed good precision, accuracy, and linearity. In all analyzed goji fruits, glucose and fructose were the predominant sugars, while sucrose content was about ten times lower than each monose. It was observed that glucose and fructose were detected in comparable quantities in all considered samples. Quantitative analysis showed that fructose, glucose, and sucrose content ranged from 154.20 to $259.13 \mathrm{mg} \mathrm{g}^{-1}$, from 152.92 to $284.60 \mathrm{mg} \mathrm{g}^{-1}$, and from 13.75 to $36.43 \mathrm{mg} \mathrm{g}^{-1}$, respectively.

\section{Introduction}

Recently, the interest in the composition of berry fruits has grown because of increased awareness of their possible health benefits, as they are rich sources of sugars, micronutrients, and other important substances such as phytochemicals. In fact, recent studies have revealed that berry species have essential positive effects on the human health which could be mainly ascribed to the presence of several taste and health related compounds such as sugars, phenolics, and organic acids $[1,2]$. Lycium barbarum $\mathrm{L}$. is a shrub from the family Solanaceae coming from Southeast Asia and is mostly grown in China [3]. Its fruit, goji berry, has become more popular for the last few years due to its public acceptance as a "super food" with highly advantageous nutritive; in fact this fruit is a rich source of sugars with interesting nutritional value [4]. Moreover, sugars, the main soluble constituents of goji berry, have a major effect on taste and represent an index of consumer acceptability. Modern consumers are increasingly interested in their personal health and expect the foods to be not only tasty and attractive but also safe and healthy. The fruit of $L$. barbarum has a variety of important biological functions, such as enhancing immunity, antiaging, antitumor, and antioxidant. L. barbarum polysaccharides and total sugars in the fruit constitute the major aspect of the medicinal quality of goji fruit; for this reason the evaluation of its sugar composition is important [5].

The sucrose metabolism-related sugars in fruits mainly include glucose, fructose, and sucrose [6]. There are some scientific evidences that sucrose is the primary form of transported sugar in tomatoes $[7,8]$, but it only accounts for a small percentage, while glucose and fructose, in approximately equal contents, reach over $50 \%$ of the total water-soluble sugars in fruits [9].

In relation to the analytical aspects, amino-bonded phase HPLC with refractive index (RI) detectors has been extensively used for sugar analysis [10]. However, evaporative light scattering detector (ELSD) presents numerous advantages compared to RI detector, such as the sensitivity, the stability, and the compatibility with gradient elution [11]. In the present study, a simple, rapid, sensitive, selective, and reliable HPLC method using ELSD was developed and validated. Then it was successfully used for the simultaneous determination of glucose, fructose, and sucrose in commercial samples of goji berries.

\section{Materials and Methods}

2.1. Goji Samples. Sixteen commercial samples of goji berries (L. barbarum) were collected in 2015 from different sellers 
TABLE 1: Goji berry samples.

\begin{tabular}{lcccc}
\hline Sample & Purchasing & Origin & Selling size & Species \\
\hline I & Herbalist's shop & Ningxia-RPC & By weight (100 g) & Unspecified \\
II & Herbalist's shop & Ningxia-RPC & By weight (100 g) & L. barbarum \\
III & Drugstore & Tibet & By weight $(100 \mathrm{~g})$ & L. barbarum \\
IV & Herbalist's shop & Ningxia-RPC & By weight $(100 \mathrm{~g})$ & L. barbarum \\
V & Drugstore & Agriculture no EU & Plastic bag (100 g) & Unspecified \\
VI & Herbalist's shop & Tibet & By weight (100 g) & L. barbarum \\
VII & Herbalist's shop & Ningxia-RPC & By weight (100 g) & L. barbarum \\
VIII & Herbalist's shop & Tibet & By weight (100 g) & Unspecified \\
IX & Herbalist's shop & Tibet & By weight (100 g) & L. barbarum \\
X & Supermarket & Agriculture no EU & Plastic bag (80 g) & L. barbarum \\
XI & Supermarket & China & Plastic bag (80 g) & L. barbarum \\
XII & Supermarket & Not reported & Plastic bag (35 g) & Unspecified \\
XIII & Herbalist's shop & Ningxia-RPC & By weight (100 g) & L. barbarum \\
XIV & Drugstore & Mongolia & Bag with pressure lock (100 g) & L. barbarum \\
XV & Supermarket & China & Plastic container (150 g) & L. barbarum \\
XVI & Supermarket & Qinghai-Tibetan Plateau & Plastic bag (100 g) & Unspecified \\
\hline
\end{tabular}

(herbalist's shops, drugstores, and supermarkets). Some information about the samples investigated in this work has been described in Table 1. The samples were stored in a dry place in the dark at room temperature until analyses. The samples were tested shortly after opening of the package and then immediately closed and left at room temperature in a dry place in the dark.

2.2. Reagents. HPLC grade acetonitrile (ACN), chloroform $\left(\mathrm{CHCl}_{3}\right)$, and analytical grade reference compounds, D(-)-fructose ( $\geq 99 \% \mathrm{GC}), \mathrm{D}-(+)$-glucose $(\geq 99.5 \% \mathrm{GC})$, and D-(+)-sucrose $(\geq 99.5 \%$ GC), were purchased from SigmaAldrich (Milano, Italy), whereas deionized water (>18 MX cm resistivity) was obtained from Milli-Q SP Reagent Water System (Millipore, Bedford, MA, USA).

2.3. Preparation of Standard Solution. Stock solutions of fructose, glucose, and sucrose were prepared in bidistilled water by weighing $2.5231,2.5120$, and $2.5363 \mathrm{~g}$, respectively, and bringing the volume to $100 \mathrm{~mL}$. The standard solution was diluted to five appropriate concentrations ranging from 2.50 to $0.31 \mathrm{mg} \mathrm{mL}^{-1}$. Stock solutions of the sugars were stable for 1 month at $4^{\circ} \mathrm{C}$ in the refrigerator. The working standard solutions were prepared as needed by appropriate dilutions of the concentrated stock solutions in the bidistilled water. Standard solutions were prepared fresh daily.

2.4. HPLC Instrumentation and Chromatographic Condition. The HPLC analyses were carried out using a LC-10ADvp pump (Shimadzu Corp., Kyoto, Japan) and ELSD (Sedex 55, S.E.D.E.RE., France), operating at $60^{\circ} \mathrm{C}$ and nitrogen pressure of $230 \mathrm{kPa}$. Standard and sample solutions $(20 \mu \mathrm{L})$ were directly injected on a Platinum Amino column $(5 \mu \mathrm{m}$, $250 \mathrm{~mm} \times 4.6 \mathrm{~mm}$ i.d.; Grace, Lokeren, Belgium), maintained at a temperature of $20^{\circ} \mathrm{C}$ in a column oven (CTO-10ASvp, Shimadzu).

HPLC analysis was carried out by isocratic elution for 20 minutes using the mixture $\mathrm{ACN}: \mathrm{H}_{2} \mathrm{O}(80: 20, \mathrm{v} / \mathrm{v})$ at a flow rate of $1.2 \mathrm{~mL} \mathrm{~min}^{-1}$. The mobile phase was degassed by ultrasonic bath (Astrason Heat Systems, New Highway, Farmingdale, NY) prior to use. After each analysis, the column was washed with water. The chromatograms were acquired and the data handled using the Class-VP software (Shimadzu). All solutions of samples were filtered through 0.45 nylon membrane (Advanced Microdevices Pvt. Ltd., Ambala, India) before use.

2.5. Calibration Curves and Limit of Detection and Quantification. Twenty $\mu \mathrm{L}$ of each solution was injected in duplicate for the construction of calibration curves. The calibration curves were obtained by plotting peak area versus concentration of each sugar. The linearity was evaluated by linear regression analysis calculated by the least square regression method. The limits of detection (LOD) and limits of quantification (LOQ) were calculated according to the statistical method reported in Federal Register [12]. The LOD and LOQ values were experimentally verified by injections of standard solutions of the compounds at the LOD and LOQ concentrations.

2.6. Accuracy. The recovery test was used to evaluate the accuracy of the method. The recovery was evaluated after extraction of analytes from some selected goji berry samples spiked with a mixture of known amounts of fructose, glucose, and sucrose standards $\left(1.0,2.0\right.$, and $\left.3.0 \mathrm{mg} \mathrm{mL}^{-1}\right)$. Then the spiked analytes were analyzed in triplicate as reported in Section 2.4 in order to assess the effectiveness and accuracy of the extraction step.

The percentage of recovery was calculated by using the following formula:

$$
\begin{aligned}
\operatorname{Recovery}(\%)= & \frac{[\text { analyte }]_{\text {spiked }}-[\text { analyte }]_{\text {unspiked }}}{[\text { analyte }]_{\text {added }}} \\
& \times 100,
\end{aligned}
$$

where [analyte] $]_{\text {spiked }}$ is the recorded amount of sugar observed in the spiked sample, [analyte] $]_{\text {unspiked }}$ is the amount 
TABLE 2: Regression parameters and LOD and LOQ for fructose, glucose, and sucrose.

\begin{tabular}{|c|c|c|c|c|c|c|}
\hline Sugar & $\begin{array}{c}\text { Retention time } \\
(\mathrm{min})\end{array}$ & Regression equation & $\begin{array}{l}\text { Linearity range } \\
\left(\mathrm{mg} \mathrm{mL}^{-1}\right)\end{array}$ & $r^{2}$ & $\begin{array}{l}\text { LOD } \\
(\mu \mathrm{g}) \\
\end{array}$ & $\begin{array}{c}\text { LOQ } \\
(\mu \mathrm{g})\end{array}$ \\
\hline Fructose & 7.25 & $y=4100.34 x-642.06$ & $0.31-2.50$ & 0.9986 & 1.2 & 3.6 \\
\hline Glucose & 8.37 & $y=3699.65 x-603.23$ & $0.31-2.50$ & 0.9981 & 1.2 & 3.6 \\
\hline Sucrose & 13.59 & $y=3654.10 x-463.42$ & $0.31-2.50$ & 0.9998 & 1.0 & 3.0 \\
\hline
\end{tabular}

of sugar observed in the unspiked sample, and [analyte $]_{\text {added }}$ is the amount of the sugar standards added in the spiked sample.

2.7. Precision. The intraday and interday precision of method were evaluated by six replicate injections of the standard solution (containing $0.62 \mathrm{mg} \mathrm{mL}^{-1}$ of each analyte) for three consecutive days. The repeatability and reproducibility of the developed method were assessed by evaluating the intraand interday percent relative standard deviation (\% RSD) of retention times $\left(t_{R}\right)$, peak areas $\left(P_{A}\right)$, and sugar concentrations $\left(C_{S}\right)$.

2.8. Sample Preparation for the Determination of Sugars. The extraction of sugars from goji berry samples was adapted from a method described by Broeckling et al. [13]. For this, $5 \mathrm{~g}$ of goji berry tissue was homogenized in blender (Oster, model 869-50R, USA) for 2 minutes using $50 \mathrm{~mL}$ of bidistilled water; after that an equal volume of $\mathrm{CHCl}_{3}(50 \mathrm{~mL})$ was added. The obtained mixture was vortexed for 5 minutes and then incubated at $50^{\circ} \mathrm{C}$ for 30 minutes under magnetic stirring (F80 Model, FALC Instruments s.r.l., Treviglio, Bergamo, Italy). The extract was followed by centrifugation at $6500 \mathrm{rpm}$ for 10 minutes; then the supernatant was separated and transferred to $250 \mathrm{~mL}$ flask and subjected to Rotavapor (B480 Model, Büchi, Italy) for 5 minutes and successively to nitrogen flow for 10 minutes for removing $\mathrm{CHCl}_{3}$ traces. All solutions of samples were filtered through 0.45 nylon membrane (Advanced Microdevices Pvt. Ltd., Ambala, India) and then analyzed in HPLC, as described in Section 2.4.

2.9. Statistical Analysis. The results of the analyses are expressed as the mean value and standard deviation (SD) based on three replicates. Microsoft Excel 2007 (Microsoft Corporation, Redmond, WA, USA) was used for data analysis.

\section{Results and Discussion}

This study presents an analytical HPLC method for the simultaneous analysis and quantification of the major sugars present in goji berries. The representative chromatograms for the standard mixture and sample of goji berry, using Platinum column operating with $\mathrm{ACN}: \mathrm{H}_{2} \mathrm{O}(80: 20, \mathrm{v} / \mathrm{v})$ as mobile phase at $20^{\circ} \mathrm{C}$, are shown in Figures 1 and 2, respectively. The chromatographic peaks were identified by comparing their retention times with reference compounds and spiking of samples with the reference compounds. The chromatograms reported in Figures 1 and 2 showed that sugars were well

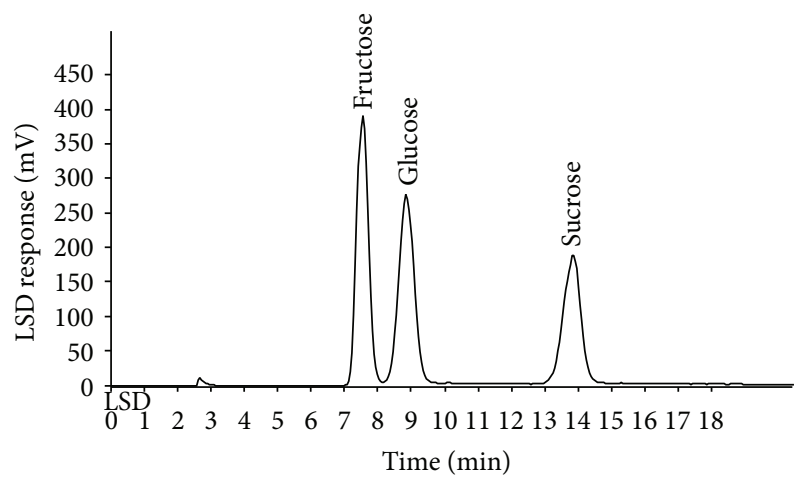

FIGURE 1: HPLC-ELSD profile of fructose, glucose, and sucrose standard compounds.

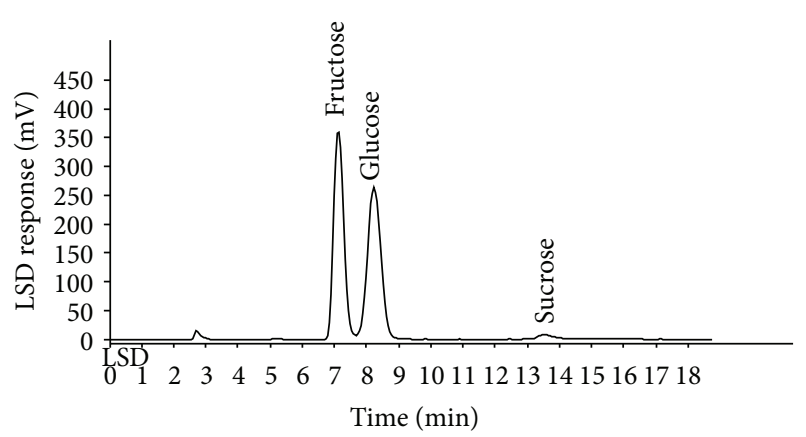

FIGURE 2: HPLC-ELSD profile of a sample of goji berries.

resolved and then their quantitative determination in goji berries was possible.

3.1. Method Validation. The reliability of the method in terms of linearity, precision, and accuracy was evaluated. In Table 2 the regression equations and LOD and LOQ for fructose, glucose, and sucrose are shown. The method allowed the separation of all analytes in short time $(15 \mathrm{~min})$. The linear regression performed for each compound gave a regression coefficient $\left(r^{2}\right)$ higher than 0.9980 (Table 2), which showed a linear relationship between the chromatographic response areas and concentrations for all compounds.

In Table 3, the results of precision and recovery for the considered compounds are reported. Day-to-day variations of retention times, peak areas, and analyte concentrations were determined on three different days using standard solution containing fructose, glucose, and sucrose. The results showed that intra- and interday \% RSD of the retention times, peak areas, and concentrations had low values (less than 
TABLE 3: Precision and recovery data for retention times, peak areas, and sugar concentrations.

\begin{tabular}{|c|c|c|c|c|c|c|c|c|c|c|c|c|c|c|c|}
\hline \multirow{3}{*}{ Sugar } & \multicolumn{9}{|c|}{ Intraday precision $(n=6$, mean $), \%$ RSD } & \multirow{2}{*}{\multicolumn{3}{|c|}{$\begin{array}{c}\text { Interday precision } \\
(n=18, \text { mean }), \% \text { RSD }\end{array}$}} & \multicolumn{3}{|c|}{ Recovery (\%) } \\
\hline & \multicolumn{3}{|c|}{ Day 1} & \multicolumn{3}{|c|}{ Day 2} & \multicolumn{3}{|c|}{ Day 3} & & & & Spiked amount & & \\
\hline & $t_{R}{ }^{\mathrm{a}}$ & $P_{A}^{\mathrm{b}}$ & $C_{S}{ }^{\mathrm{c}}$ & $t_{R}{ }^{\mathrm{a}}$ & $P_{A}^{\mathrm{b}}$ & $C_{S}{ }^{\mathrm{c}}$ & $t_{R}{ }^{\mathrm{a}}$ & $P_{A}^{\mathrm{b}}$ & $C_{S}{ }^{c}$ & $t_{R}{ }^{\mathrm{a}}$ & $P_{A}{ }^{\mathrm{b}}$ & $C_{S}{ }^{c}$ & $\left(\mathrm{mg} \mathrm{mL}^{-1}\right)$ & Mean & $\%$ RSD \\
\hline \multirow{3}{*}{ Fructose } & & & & & & & & & & & & & 1.0 & 95.4 & \\
\hline & 0.10 & 0.41 & 0.24 & 0.11 & 0.52 & 0.28 & 0.14 & 0.65 & 0.34 & 0.13 & 0.41 & 0.37 & 2.0 & 97.0 & 1.12 \\
\hline & & & & & & & & & & & & & 3.0 & 96.3 & \\
\hline \multirow{3}{*}{ Glucose } & & & & & & & & & & & & & 1.0 & 98.2 & \\
\hline & 0.26 & 0.79 & 0.97 & 0.28 & 0.74 & 0.92 & 0.31 & 0.76 & 0.95 & 0.25 & 0.82 & 1.07 & 2.0 & 99.0 & 1.02 \\
\hline & & & & & & & & & & & & & 3.0 & 98.0 & \\
\hline \multirow{3}{*}{ Sucrose } & & & & & & & & & & & & & 1.0 & 95.6 & \\
\hline & 0.11 & 0.26 & 0.15 & 0.12 & 0.32 & 0.12 & 0.14 & 0.29 & 0.19 & 0.16 & 0.36 & 0.21 & 2.0 & 97.0 & 1.21 \\
\hline & & & & & & & & & & & & & 3.0 & 99.0 & \\
\hline
\end{tabular}

${ }^{\mathrm{a}} \%$ RSD of retention time.

$\mathrm{b}_{\%}$ RSD of peak area.

${ }^{c} \%$ RSD of sugar concentration.

$1.07 \%)$. Recovery studies were carried out to determine the accuracy of the method; a goji berry sample was analyzed before and after the addition of known amounts of fructose, glucose, and sucrose. The results indicated that the developed analytical method had good accuracy, with satisfactory recovery (95.4-99.0\%) for the considered analytes. Therefore, the developed method had good linearity, precision, and accuracy for the simultaneous quantitative evaluation of fructose, glucose, and sucrose in fruit of L. barbarum.

3.2. Optimization of Sample Extraction Method. In order to optimize the extraction yield, a method was adapted from Broeckling et al. [13] and was modified to obtain the best conditions for HPLC analysis. Sample aliquot of $5 \mathrm{~g}$ was used in order to extract reproducibly sugars from commercial goji berries. This fruit is present on market as "sun-dried" product and in this condition any analysis with good reproducibility is very hard to perform. In fact, due to the gluey nature of the fruits, grinding is very difficult; therefore classical mill pulverization is not feasible, whereas anhydrification technique such as lyophilization does not resolve the problem [14]. The described method used the berries without pretreatments; in fact the fruits were directly homogenized with bidistilled water; in this way both homogenization and a first extraction step were carried out. The second step was performed using the same volume of chloroform with respect to water at $50^{\circ} \mathrm{C}$ for 30 minutes; this was an important clean-up step to complete the extraction procedure; in fact the goji fruit is a very complex matrix with a significative amount of pigments and lipids that are extracted with chloroform, the discarded phase. Then, at the end of clean-up step (after $30 \mathrm{~min}$ ), the sugar content was totally extracted from goji berries and successively it was possible to perform the HPLC analysis.

3.3. Optimization of HPLC-ELSD Conditions. For the best results, the following detector parameters were optimized.

3.3.1. Mobile Phase and Column Temperature. Different ratios of acetonitrile and water were tested. In general, by increasing water percentage in the mobile phase, the retention times were lower, but the resolution decreased. So the optimum composition of the mobile phase was selected as ACN : $\mathrm{H}_{2} \mathrm{O}$ $(80: 20, \mathrm{v} / \mathrm{v})$.

Column temperature was regulated at $20^{\circ} \mathrm{C}$. In this condition the background noise was eliminated considerably and an improved response value was observed.

3.3.2. Drift Tube Temperature. The HPLC analysis with light scattering technique offers the advantage to detect the organic molecules by their mass and hence it is useful in quantitative determination of non-UV sensitive compounds. An important parameter for optimizing ELSD conditions is the drift tube temperature [15]. Good peak symmetries and efficiencies were obtained by means of a drift tube temperature at $60^{\circ} \mathrm{C}$.

3.4. Application for the Determination of Sugars in Goji Berries. The developed HPLC-ELSD method was applied to analyze fructose, glucose, and sucrose in sixteen samples of goji berries. In all samples fructose, glucose, and sucrose were successfully identified in 15 minutes (Figure 2). Table 4 reports the content of sugars in goji samples examined in this study. In all samples, fructose and glucose were recorded in large amount (154.20-259.13 $\mathrm{mg} \mathrm{g}^{-1}$ and $152.92-$ $284.60 \mathrm{mgg}^{-1}$, resp.), while sucrose content was about ten times lower (13.75-36.43 $\mathrm{mg} \mathrm{g}^{-1}$ ) than each monose. MikulicPetkovsek and collaborators [16] reported $23.1 \mathrm{~g} \mathrm{~kg}^{-1}$ for both fructose and glucose and $0.38 \mathrm{~g} \mathrm{~kg}^{-1}$ for sucrose, but they considered fresh cultivated berries. Zheng and collaborators [17], instead, reported content similar to our results and underlined the different content of hexoses with respect to sucrose: the former accounted for $97.92 \%$ of the total content of the three sugars plus the starch $(0.026 \%)$, while the latter accounted for only $1.82 \%$. As the results obtained in this study are in agreement with those reported by the cited authors for ripe fruits, we can conclude that all the analyzed goji samples reached the ripening stage. This research helps expand knowledge on goji simple sugars, since very few data are available in literature. In fact most of the studies focused 
TABle 4: Fructose, glucose, and sucrose contents $\left(\mathrm{mg} \mathrm{g}^{-1}\right.$, mean values $\pm \mathrm{SD}, n=3$ ) in goji samples.

\begin{tabular}{lccc}
\hline Sample & Fructose & Glucose & Sucrose \\
\hline I & $186.02 \pm 1.84$ & $183.42 \pm 1.91$ & $21.84 \pm 0.92$ \\
II & $196.53 \pm 0.71$ & $180.34 \pm 1.84$ & $21.12 \pm 0.85$ \\
III & $214.41 \pm 9.83$ & $183.52 \pm 25.39$ & $33.93 \pm 2.83$ \\
IV & $193.14 \pm 3.82$ & $172.11 \pm 0.92$ & $19.75 \pm 0.99$ \\
V & $178.60 \pm 19.59$ & $182.34 \pm 19.59$ & $28.70 \pm 1.27$ \\
VI & $194.02 \pm 7.07$ & $189.72 \pm 3.11$ & $23.32 \pm 0.00$ \\
VII & $208.34 \pm 0.00$ & $203.15 \pm 3.75$ & $24.91 \pm 0.00$ \\
VIII & $202.44 \pm 20.22$ & $179.80 \pm 18.46$ & $20.22 \pm 1.70$ \\
IX & $154.20 \pm 1.20$ & $152.92 \pm 0.57$ & $13.75 \pm 0.64$ \\
X & $243.43 \pm 27.79$ & $243.41 \pm 17.82$ & $20.60 \pm 1.27$ \\
XI & $239.54 \pm 3.32$ & $259.72 \pm 1.70$ & $34.61 \pm 1.68$ \\
XII & $233.21 \pm 16.33$ & $221.14 \pm 8.84$ & $19.34 \pm 1.34$ \\
XIII & $184.23 \pm 2.76$ & $171.63 \pm 3.68$ & $18.50 \pm 1.84$ \\
XIV & $236.20 \pm 6.72$ & $222.01 \pm 0.00$ & $22.81 \pm 1.13$ \\
XV & $190.81 \pm 0.00$ & $208.52 \pm 6.29$ & $36.43 \pm 1.27$ \\
XVI & $259.13 \pm 2.76$ & $284.60 \pm 6.51$ & $26.25 \pm 1.84$ \\
\hline
\end{tabular}

on the polysaccharide fraction $[18,19]$, characterized by a variety of biological activities.

\section{Conclusions}

This study presents an analytical HPLC method for the simultaneous analysis and quantification of the major sugars in goji berries. By the obtained results we can conclude that this method is suitable to separate and quantify fructose, glucose, and sucrose without derivatization in less than 15 minutes. The regression equations revealed good linear relationships $\left(r^{2}=0.9981-0.9998\right)$ within test ranges. Moreover, LOD and LOQ for the considered analytes were in the range of $1.0-1.2 \mu \mathrm{g}$ and $3.0-3.6 \mu \mathrm{g}$, respectively. The results of analysis carried out on sixteen goji samples were in good agreement with those previously obtained by other authors. Then, the proposed HPLC-ELSD method can be used to quantify simultaneously fructose, glucose, and sucrose in goji fruits.

\section{Conflict of Interests}

The authors declare that there is no conflict of interests regarding the publication of this paper.

\section{References}

[1] I. Badjakov, M. Nikolova, R. Gevrenova, V. Kondakova, E. Todorovska, and A. Atanassov, "Bioactive compounds in small fruits and their influence on human health," Biotechnology \& Biotechnological Equipment, vol. 22, no. 1, pp. 581-587, 2008.

[2] M. Forino, L. Tartaglione, C. Dell'Aversano, and P. Ciminiello, "NMR-based identification of the phenolic profile of fruits of Lycium barbarum (goji berries). Isolation and structural determination of a novel $N$-feruloyl tyramine dimer as the most abundant antioxidant polyphenol of goji berries," Food Chemistry, vol. 194, pp. 1254-1259, 2016.

[3] A. M. Lu and M. L. Wang, "On the identification of the original plants in the modernization of Chinese herbal medicine-an example from the taxonomy and exploition of 'Gouqi'" Acta Botanica Boreali-Occidentalia Sinica, vol. 23, pp. 1077-1083, 2003.

[4] H. Amagase and N. R. Farnsworth, "A review of botanical characteristics, phytochemistry, clinical relevance in efficacy and safety of Lycium barbarum fruit (Goji)," Food Research International, vol. 44, no. 7, pp. 1702-1717, 2011.

[5] O. Potterat, "Goji (Lycium barbarum and L. chinense): phytochemistry, pharmacology and safety in the perspective of traditional uses and recent popularity," Planta Medica, vol. 76, no. 1, pp. 7-19, 2010.

[6] Y.-M. Lu and D.-P. Zhang, "Accumulation of sugars in developing fruits," Plant Physiology Communications, vol. 36, no. 3, pp. 258-265, 2000.

[7] A. J. Walker and L. C. Ho, "Carbon translocation in the tomato: carbon import and fruit growth," Annals of Botany, vol. 41, no. 4, pp. 813-823, 1977.

[8] P. Bucheli and S. Dévaud, "Sugar accumulation in tomato and partial purification of buffer-insoluble invertase," Phytochemistry, vol. 36, no. 4, pp. 837-841, 1994.

[9] N. L. Robinson, J. D. Hewitt, and A. B. Bennett, "Sink metabolism in tomato fruit. I. Developmental changes in carbohydrate metabolizing enzymes," Plant Physiology, vol. 87, no. 3, pp. 727-730, 1988.

[10] M. Karkacier, M. Erbas, M. K. Uslu, and M. Aksu, "Comparison of different extraction and detection methods for sugars using amino-bonded phase HPLC," Journal of Chromatographic Science, vol. 41, no. 6, pp. 331-333, 2003.

[11] M. Ganzera and H. Stuppner, "Evaporative Light Scattering Detection (ELSD) for the analysis of natural products," Current Pharmaceutical Analysis, vol. 1, no. 2, pp. 135-144, 2005.

[12] International Conference on Harmonization (ICH) Q2B, "Validation of analytical procedures: methodology," Federal Register, vol. 62, no. 96, pp. 27463-27467, 1997.

[13] C. D. Broeckling, D. V. Huhman, M. A. Farag et al., "Metabolic profiling of Medicago truncatula cell cultures reveals the effects of biotic and abiotic elicitors on metabolism," Journal of Experimental Botany, vol. 56, no. 410, pp. 323-336, 2005.

[14] A. Karioti, M. C. Bergonzi, F. Vincieri, and A. R. Bilia, "Validated method for the analysis of goji berry, a rich source of zeaxanthin dipalmitate," Journal of Agricultural and Food Chemistry, vol. 62, no. 52, pp. 12529-12535, 2014.

[15] B. Singh and R. Rastogi, "Chemical examination of Picrorhiza kurrooa Benth.: part VI. Reinvestigation of kutkin," Indian Journal of Chemistry, vol. 10, no. 1, pp. 29-31, 1972.

[16] M. Mikulic-Petkovsek, V. Schmitzer, A. Slatnar, F. Stampar, and R. Veberic, "Composition of sugars, organic acids, and total phenolics in 25 wild or cultivated berry species," Journal of Food Science, vol. 77, no. 10, pp. C1064-C1070, 2012.

[17] G.-Q. Zheng, Z.-Y. Zheng, X. Xu, and Z.-H. Hu, "Variation in fruit sugar composition of Lycium barbarum L. and Lycium chinense Mill. of different regions and varieties," Biochemical Systematics and Ecology, vol. 38, no. 3, pp. 275-284, 2010.

[18] Q. Zhang, X. Lv, T. Wu et al., "Composition of Lycium barbarum polysaccharides and their apoptosis-inducing effect on human hepatoma SMMC-7721 cells," Food and Nutrition Research, vol. 59, Article ID 28696, 2015.

[19] M. Zhang, X. Tang, F. Wang, Q. Zhang, and Z. Zhang, "Characterization of Lycium barbarum polysaccharide and its effect on human hepatoma cells," International Journal of Biological Macromolecules, vol. 61, pp. 270-275, 2013. 

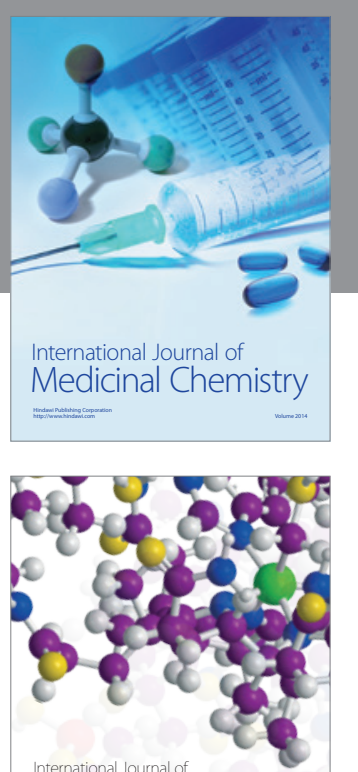

Carbohydrate Chemistry

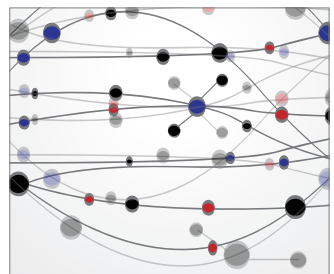

The Scientific World Journal
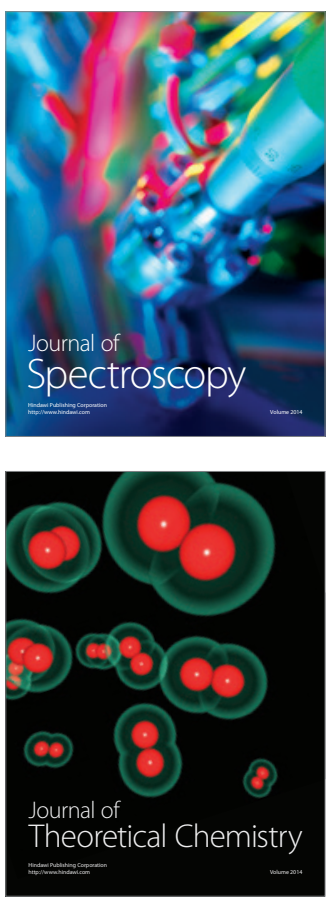
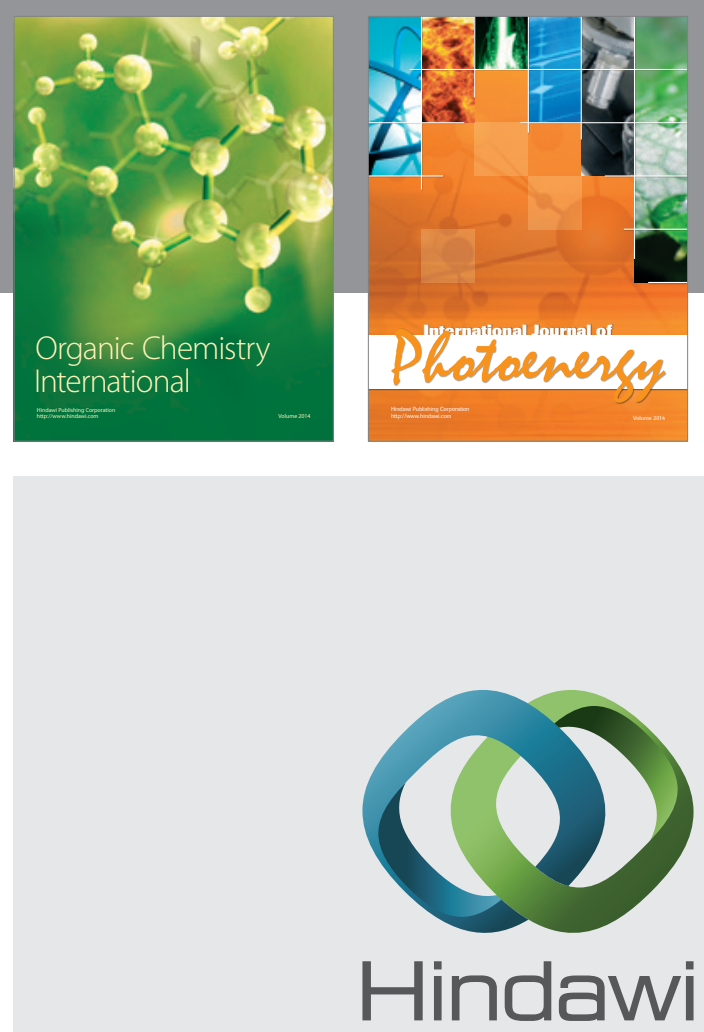

Submit your manuscripts at

http://www.hindawi.com

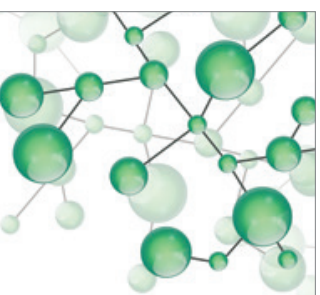

International Journal of

Inorganic Chemistry

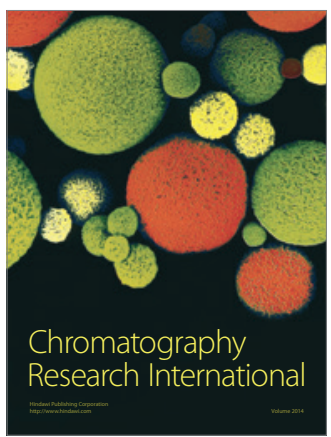

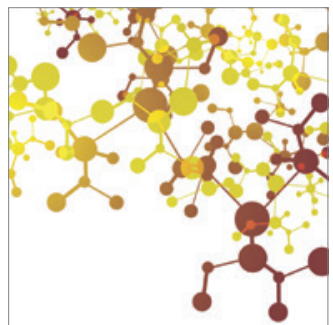

Applied Chemistry
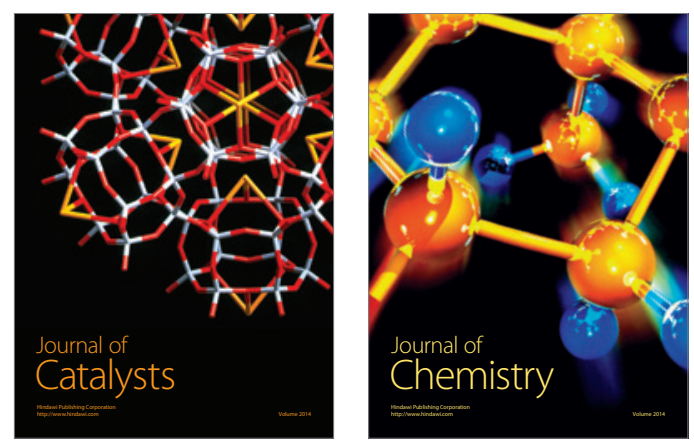
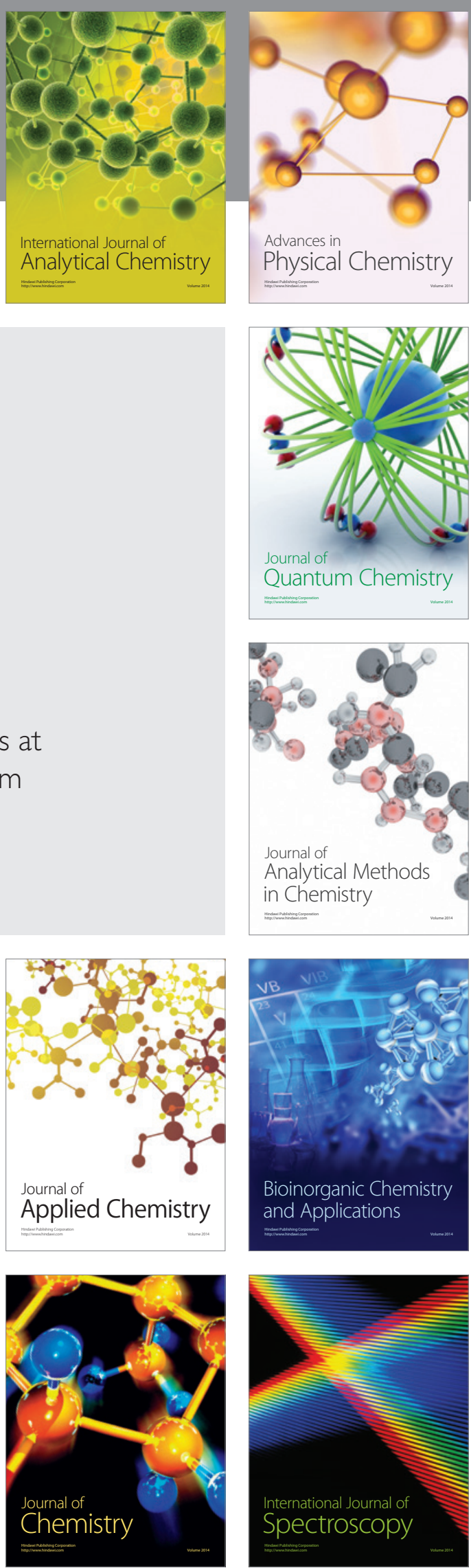